\title{
Pengaruh Personal Hygiene Terhadap Terjadinya Penyakit Kusta di Wilayah Kerja Puskesmas Sukatani Kabupaten Purwakarta Tahun 2020
}

\author{
Ahmad Zaelani, Anna Sunita, Sri Utami \\ Program Studi Ilmu Kesehatan Masyarakat, Universitas Respati Indonesia \\ Email : zaelania873@gmail.com
}

\begin{abstract}
Abstrak
Indonesia berada di peringkat ketiga jumlah kasus kusta. Penyakit kusta menyebabkan kerusakan pada kulit, syaraf, anggota gerak dan mata. Personal hygiene mempengaruhi keberhasilan penyembuhan, dan sekitar $70 \%$ dapat sembuh sendiri (determinate). Penelitian ini bertujuan untuk mengetahui pengaruh personal hygiene terhadap kejadian penyakit kusta di wilayah kerja Puskesmas Sukatani Kabupaten Purwakarta tahun 2020. Penelitian ini menggunakan metode kuantitatif dengan rancangan case control. Teknik pengumpulan data menggunakan kuesioner. Sampel sebanyak 116 responden dengan perbandingan 1:3, yaitu 29 kasus dan 87 kontrol. Teknik pengambilan sampel berdasarkan daftar kasus kusta dalam pengobatan di Puskesmas. Sedangkan kontrol merupakan tetangga terdekat. Analisis multivariat menggunakan uji regresi logistik binary. Hasil penelitian menunjukkan adanya hubungan yang bermakna antara jenis pekerjaan $(p=0,023)$, pengetahuan $(p=0,007)$, riwayat kontak $(p=0,000)$, kondisi fisik rumah $(p=0,001)$, sumber air bersih $(p=0,005)$, kelembaban $(p=0,006)$, dan suhu kamar $(p=0,028)$. Ada pengaruh personal hygiene $(p=0,003)$, dengan OR 4,295 (95\% Cl: 1,708 10,803), artinya responden yang memiliki personal hygiene buruk berisiko 4,295 kali untuk sakit kusta dibanding responden yang memiliki personal hygiene baik, setelah dikontrol oleh variabel riwayat kontak, pengetahuan, kelembaban kamar, kondisi fisik rumah, dan jenis pekerjaan. Disarankan untuk meningkatkan personal hygiene penduduk melalui promosi kesehatan mengenai pengetahuan penyakit kusta, serta penyediaan sarana sumber air bersih.
\end{abstract}

\section{Kata kunci : Penyakit Kusta, Personal Hygiene, Riwayat Kontak Daftar Pustaka : : 14 (1999-2019)}

\begin{abstract}
Indonesia is ranked third in leprosy cases number. Leprosy causes damage to skin, nerves, limbs and eyes. Personal hygiene affects healing success, and about $70 \%$ heal itself (determinate). This study aims to determine effect of personal hygiene on leprosy incidence in Sukatani Public Health Center, Purwakarta Regency, 2020. This study used quantitative method with case control design. Data collection techniques using questionnaire. Sample were 116 respondents with ratio 1:3, consist of 29 cases and 87 controls. Sampling technique was based on leprosy cases list at Health Center. Control is closest neighbor. Multivariate analysis using binary logistic regression test. Results showed that there was significant relationship between work type $(p=0.023)$, knowledge $(p=0.007)$, contact history $(p=0.000)$, house's physical condition $(p=0.001)$, clean water sources $(p=0.005)$, humidity $(p=0.006)$, and room temperature $(p=0.028)$. There is effect of personal hygiene $(p=0.003)$, with an OR of $4.295(95 \% \mathrm{Cl}: 1.708-10.803)$, meaning that respondents who have poor personal hygiene risked 4.295 times for leprosy compared to respondents who have good personal hygiene, after being controlled by contact history, knowledge, room humidity, house's physical condition, and working type. It is recommended to improve population personal hygiene through health promotion regarding knowledge of leprosy, as well as the provision of clean water sources.
\end{abstract}

Keywords: Leprosy, Personal Hygiene, Contact History

Reference : 14 (1999-2019)

http://ejournal.urindo.ac.id/index.php/kesehatan

Article History :

Sumbitted 19 Juni 2021 Accepted 30 Desember 2021, Published 31 Desember 2021 


\section{PENDAHULUAN}

Penyakit kusta tersebar di seluruh dunia, dua hingga tiga juta orang diperkirakan menderita kusta. Menurut World Health Organization (WHO) tercatat pada tahun 2017, terdapat 210.671 penderita kusta yang dilaporkan dari 38 negara di semua regional. Asia Tenggara menjadi penyumbang kasus baru kusta paling banyak yaitu 153.487, sedangkan Eropa menjadi penyumbang kasus baru kusta paling sedikit dengan jumlah kasus sebanyak 33 kasus. Data WHO Tahun 2011, Indonesia ada di peringkat ketiga, dan pada tahun 2018 terdapat sebanyak 26.826 kasus, kenaikan kasus baru kusta mencapai 6,5\% dari tahun sebelumnya. ${ }^{1}$

Propinsi Jawa Barat, dengan penderita kusta baru tercatat pada tahun 2017 adalah sebanyak 1.813 kasus. $^{2} \quad$ Kabupaten Purwakarta, dari tahun 2017 ke tahun 2018 mengalami kenaikan kasus berkisar 14,2\% yaitu 97 kasus menjadi 113 kasus, dan dari tahun 2018 ke tahun 2019 mengalami penurunan kasus berkisar 3,6\% menjadi 109 kasus. ${ }^{3}$ Penderita kusta yang melakukan pengobatan di Puskesmas Sukatani Kabupaten Purwakarta pada tahun 2019 sebanyak 29 kasus dan tahun 2020 priode Januari-Maret sebanyak 6 kasus baru. ${ }^{4}$

Penyakit kusta adalah penyakit yang disebabkan oleh bakteri mycobacterium leprae, kusta menyerang berbagai bagian tubuh diantaranya saraf dan kulit, bila tidak ditangani, kusta sangat progresif menyebabkan kerusakan pada kulit, sarafsaraf, anggota gerak dan mata. Dampak kesehatan akibat kusta tidak hanya masalah kesehatan saja tetapi sampai pada masalah ekonomi, pendidikan, sosial budaya dan nasional. Sayangnya sebagian masyarakat masih beranggapan bahwa penyakit kusta adalah penyakit kutukan. ${ }^{5}$

Personal Hygiene merupakan penentu keberhasilan dalam menyembuhkan Penyakit kusta, dimana sekitar $70 \%$ dapat sembuh sendiri (determinate) tergantung perawatan dan pemeliharaan kesehatan diri, memperbaiki dan mempertinggi nilai kesehatan, serta mencegah timbulnya penyakit sebelum datang. ${ }^{5}$ Hasil penelitian Muharry 2014, terdapat hubungan bermakna antara personal hygiene dengan kusta, dimana seseorang yang memiliki kondisi kebersihan perorangan buruk mempunyai risiko 12,103 kali untuk terjadi kusta $\mathrm{OR}=12,103(95 \% \mathrm{Cl}=3,855-38,000) .{ }^{6}$

Berdasarkan hasil uji bivariat oleh Tarmisi, dkk 2016, menunjukan dari 31 responden yang mempunyai personal hygiene buruk, terdapat 15 kasus (71,4 \%) mengalami kusta, sedangkan dari 53 responden dengan personal hygine baik yang mempunyai personal hygiene baik, hanya terdapat 6 kasus $(28,6 \%)$ yang mengalami kusta. dari hasil uji statistik 
menunjukan $\mathrm{OR}=7,344(\mathrm{Cl} 95 \%=2,435-$ $22,144)^{7}$

Faktor yang ikut berperan pada terjadinya penyakit kusta salah satunya adalah faktor perilaku individu, Kondisi sehat dapat dicapai dengan mengubah perilaku tidak sehat dan menciptakan lingkungan sehat di rumah tangga. Perilaku hidup bersih dan sehat (PHBS) merupakan pola hidup keluarga yang memperhatikan dan menjaga kesehatan seluruh anggota keluarga. Perilaku, lingkungan, pelayan kesehatan dan genetic merupakan faktor penyumbang terbesar kejadian penyakit. Perilaku tidak bersih dapat menjadi resiko berkembangbiaknya berbagai bakteri, termasuk bakteri kusta. ${ }^{8}$

Menanggapi masalah kusta yang begitu kompleks, pemerintah dalam hal ini Kemenetrian Kesehatan melakukan upaya pengendalian kusta yang mengusung kebijakan nasional yang berpedoman pada WHO. Pengendalian kusta di Indonesia sudah di atur dalam Permenkes No 11 Tahun 2019 tentang Penanggulangan Kusta. Puskesmas Sukatani Kabupaten Purwakarta dalam hal menangani penyakit kusta, telah membuat program diantaranya; Melakukan promosi kesehatan ke seluruh warga yang berada di kecamatan Sukatani Purwakarta, penyelidikan epidemiologi dini, menyelenggrakan komunikasi edukasi informasi dan melakukan koordinasi dengan berbagai lintas sektor untuk menanggulangi penyakit kusta. ${ }^{9}$

Resiko terjadinya penyakit kusta mempunyai hubungan erat dengan perilaku personal hygiene dan faktor-faktor lainnya yaitu umur, jenis kelamin, tingkat pendidikan, jenis pekerjaan, penghasilan, pengetahuan, riwayat kontak, akses pelayanan kesehatan, kondisi fisik rumah, sumber air bersih, ventilasi kamar, pencahayaan kamar, kelembaban kamar, suhu kamar, riwayat keturunan dan tingkat stres.

Oleh karena itu penulis tertarik meneliti "Bagaimana Apakah pengaruh perilaku personal hygiene terhadap kejadian kusta setelah dikontrol oleh variabel : umur, jenis kelamin, tingkat pendidikan, jenis pekerjaan, penghasilan, pengetahuan, riwayat kontak, akses pelayanan kesehatan, kondisi fisik rumah, sumber air bersih, ventilasi kamar, pencahayaan kamar, kelembaban kamar, suhu kamar, tingkat stres dan riwayat keluarga merupakan variabel kovariat terhadap terjadinya penyakit kusta di wilayah kerja Puskesmas Pukatani Kabupaten Purwakarta tahun 2020?".

\section{METODE}

Rancangan penelitian yang digunakan adalah Case Control. Variabel yang diteliti meliputi terjadinya penyakit kusta, personal hygiene, umur, jenis kelamin, tingkat 
pendidikan, jenis pekerjaan, penghasilan, pengetahuan, riwayat kontak, akses pelayanan kesehatan, kondisi fisik rumah, sumber air bersih, ventilasi kamar, pencahayaan kamar, kelembaban kamar, suhu kamar, tingkat stres dan riwayat keluarga (genetik). Sampel kasus adalah seseorang yang dinyatakan menderita kusta berdasarkan hasil pemeriksaan BTA positif Micobacterium leprae di Puskesmas Sukatani Kabupaten Purwakarta yang memenuhi kriteria inklusi dan eksklusi. Sampel kontrol adalah tetangga terdekat dengan penderita penyakit kusta sama dengan sampel kasus di wilayah kerja Puskesmas Sukatani Kabupaten Purwakarta yang memenuhi kriteria inklusi dan eksklusi. Jumlah sampel 116 dengan perbandingan kasus dan kontrol 1:3. Sampel diambil secara purposive sampling. Instrumen yang digunakan adalah perangkat alat tulis, kuesioner, dan perangkat komputer. Data hasil penelitian dianalisis secara univariat, bivariat dan multivariat.

HASIL PENELITIAN

Analisis Univariat

Tabel 1 Analisis Univariat

\begin{tabular}{|c|c|c|c|c|c|c|c|}
\hline \multirow{3}{*}{ Variabel } & \multirow{3}{*}{ Kategori } & \multicolumn{4}{|c|}{ Penyakit Kusta } & \multicolumn{2}{|c|}{ Total } \\
\hline & & \multicolumn{2}{|c|}{ Kontrol } & \multicolumn{2}{|c|}{ Kasus } & \multirow[b]{2}{*}{$\mathbf{N}$} & \multirow[b]{2}{*}{$\%$} \\
\hline & & $\mathbf{n}$ & $\%$ & $n$ & $\%$ & & \\
\hline \multirow{3}{*}{$\begin{array}{l}\text { Personal } \\
\text { Hygiene }\end{array}$} & Ya & 54 & 62,1 & 8 & 27,6 & 62 & 53,4 \\
\hline & Tidak & 33 & 37,9 & 21 & 72,4 & 54 & 46,6 \\
\hline & Total & 87 & 100 & 29 & 100 & 116 & 100 \\
\hline \multirow{3}{*}{ Umur } & $<20$ Tahun & 26 & 29,9 & 6 & 20,7 & 32 & 2,6 \\
\hline & $>=20$ Tahun & 61 & 70,1 & 23 & 79,3 & 84 & 72,4 \\
\hline & Total & 87 & 100 & 29 & 100 & 116 & 100 \\
\hline \multirow{3}{*}{$\begin{array}{l}\text { Jenis } \\
\text { Kelamin }\end{array}$} & Perempuan & 47 & 54 & 17 & 58,6 & 64 & 55,2 \\
\hline & Laki-laki & 40 & 46 & 12 & 41,4 & 52 & 44,8 \\
\hline & Total & 87 & 100 & 29 & 100 & 116 & 100 \\
\hline \multirow{3}{*}{$\begin{array}{l}\text { Tingkat } \\
\text { Pendidikan }\end{array}$} & Sedang & 53 & 60,9 & 12 & 41,4 & 65 & 56,0 \\
\hline & Rendah & 34 & 39,1 & 17 & 58,6 & 51 & 44,0 \\
\hline & Total & 87 & 100 & 29 & 100 & 116 & 100 \\
\hline \multirow{3}{*}{$\begin{array}{l}\text { Jenis } \\
\text { Pekerjaan }\end{array}$} & Pekerja & 44 & 50,6 & 7 & 24,1 & 51 & 44,0 \\
\hline & Buruh & 43 & 49,4 & 22 & 75,9 & 65 & 56,0 \\
\hline & Total & 87 & 100 & 29 & 100 & 116 & 100 \\
\hline \multirow{3}{*}{$\begin{array}{l}\text { Penghasila } \\
n\end{array}$} & $>=4.039 .067$ & 45 & 51,7 & 12 & 41,4 & 57 & 49,1 \\
\hline & $<4.039 .067$ & 42 & 48,3 & 17 & 58,6 & 59 & 50,9 \\
\hline & Total & 87 & 100 & 29 & 100 & 116 & 100 \\
\hline \multirow{3}{*}{$\begin{array}{l}\text { Pengetahua } \\
\mathrm{n}\end{array}$} & Ya & 54 & 62,1 & 9 & 31 & 63 & 54,3 \\
\hline & Tidak & 33 & 37,9 & 20 & 69 & 53 & 45,7 \\
\hline & Total & 87 & 100 & 29 & 100 & 116 & 100 \\
\hline
\end{tabular}




\begin{tabular}{|c|c|c|c|c|c|c|c|}
\hline \multirow{3}{*}{$\begin{array}{l}\text { Riwayat } \\
\text { Kontak }\end{array}$} & Tidak & 66 & 75,9 & 11 & 37,9 & 77 & 66,4 \\
\hline & $\mathrm{Ya}$ & 21 & 24,1 & 18 & 62,1 & 39 & 33,6 \\
\hline & Total & 87 & 100 & 29 & 100 & 116 & 100 \\
\hline \multirow{3}{*}{$\begin{array}{l}\text { Akses } \\
\text { Yankes }\end{array}$} & Tidak Jauh & 46 & 52,9 & 11 & 37,9 & 57 & 49,1 \\
\hline & Jauh & 41 & 47,1 & 18 & 62,1 & 59 & 50,9 \\
\hline & Total & 87 & 100 & 29 & 100 & 116 & 100 \\
\hline \multirow{3}{*}{$\begin{array}{l}\text { Fisik } \\
\text { Rumah }\end{array}$} & Rumah Sehat & 57 & 65,5 & 8 & 27,6 & 65 & 56,0 \\
\hline & Rumah Tidak Sehat & 30 & 34,5 & 21 & 72,4 & 51 & 44,0 \\
\hline & Total & 87 & 100 & 29 & 100 & 116 & 100 \\
\hline \multirow{3}{*}{$\begin{array}{l}\text { Sumber Air } \\
\text { Bersih }\end{array}$} & Air Tanah & 55 & 63,2 & 9 & 31 & 64 & 55,2 \\
\hline & Air Sungai & 32 & 36,8 & 20 & 69 & 52 & 44,8 \\
\hline & Total & 87 & 100 & 29 & 100 & 116 & 100 \\
\hline \multirow{3}{*}{ Ventilasi } & Memenuhi Syarat & 50 & 57,5 & 11 & 37,9 & 61 & 52,6 \\
\hline & Tidak Memenuhi Syarat & 37 & 42,5 & 18 & 62,1 & 55 & 47,4 \\
\hline & Total & 87 & 100 & 29 & 100 & 116 & 100 \\
\hline \multirow{3}{*}{$\begin{array}{l}\text { Pencahaya } \\
\text { an }\end{array}$} & Memenuhi Syarat & 48 & 55,2 & 12 & 41,4 & 60 & 51,7 \\
\hline & Tidak Memenuhi Syarat & 39 & 44,8 & 17 & 58,6 & 56 & 48,3 \\
\hline & Total & 87 & 100 & 29 & 100 & 116 & 100 \\
\hline \multirow{3}{*}{$\begin{array}{l}\text { Kelembaba } \\
\text { n }\end{array}$} & Memenuhi Syarat & 60 & 69 & 11 & 37,9 & 71 & 61,2 \\
\hline & Tidak Memenuhi Syarat & 27 & 31 & 18 & 62,1 & 45 & 38,8 \\
\hline & Total & 87 & 100 & 29 & 100 & 116 & 100 \\
\hline \multirow{3}{*}{ Suhu } & Tidak Berisiko & 58 & 66,7 & 12 & 41,4 & 70 & 60,3 \\
\hline & Berisiko & 29 & 33,3 & 17 & 58,6 & 46 & 39,7 \\
\hline & Total & 87 & 100 & 29 & 100 & 116 & 100 \\
\hline \multirow{5}{*}{$\begin{array}{l}\text { Tingkat } \\
\text { Stres }\end{array}$} & Normal & 19 & 21,8 & 3 & 10,3 & 22 & 19,0 \\
\hline & Ringan & 27 & 31,0 & 9 & 31,0 & 36 & 31,0 \\
\hline & Sedang & 31 & 35,6 & 11 & 37,9 & 42 & 36,2 \\
\hline & Berat & 10 & 11,5 & 6 & 20,7 & 16 & 13,8 \\
\hline & Total & 87 & 100 & 29 & 100 & 116 & 100 \\
\hline \multirow{3}{*}{ Genetik } & Tidak Ada Keturunan & 78 & 89,7 & 23 & 79,3 & 101 & 87,1 \\
\hline & Ada Keturunan & 9 & 10,3 & 6 & 20,7 & 15 & 12,9 \\
\hline & Total & 87 & 100 & 29 & 100 & 116 & 100 \\
\hline
\end{tabular}

Sumber : Data Primer, 2020

\section{Analisis Bivariat}

Tabel 2 Analisis Bivariat

\begin{tabular}{lccc}
\hline \multicolumn{1}{c}{ Variabel } & $\begin{array}{c}\boldsymbol{p} \\
\text { Value }\end{array}$ & OR & Cl (95\%) \\
\hline Personal Hygiene & 0,003 & 4,295 & $1,708-10,803$ \\
Umur & 0,472 & 1,634 & $0,596-4,481$ \\
Jenis Kelamin & 0,829 & 0,829 & $0,354-1,942$ \\
Tingkat Pendidikan & 0,105 & 2,208 & $0,939-5,194$ \\
Jenis Pekerjaan & 0,023 & 3,216 & $1,245-8,305$ \\
Penghasilan & 0,453 & 1,518 & $0,649-3,552$ \\
Pengetahuan & 0,007 & 3,636 & $1,481-8,926$ \\
Riwayat Kontak & 0,000 & 5,143 & $2,098-12,606$ \\
Akses Yankes & 0,238 & 1,836 & $0,777-4,339$ \\
Fisik Rumah & 0,001 & $4,, 988$ & $1,975-12,598$
\end{tabular}


Sumber Air Bersih

$\begin{array}{ccc}0,005 & 3,819 & 1,554-9,388 \\ 0,107 & 2,211 & 0,934-5,237 \\ 0,283 & 1,744 & 0,744-4,084 \\ 0,006 & 3,636 & 1,513-8,740 \\ 0,028 & 2,833 & 1,195-6,716 \\ 0,410 & - & - \\ 0,263 & 2,261 & 0,728-7,019\end{array}$

Sumber : Data Primer, 2020

Ventilasi Kamar

Pencahayaan Kamar

Kelembaban Kamar

Suhu Kamar

Tingkat Stres

0,263

2,261

Analisis Multivariat

Tabel 3 Analisis Multivariat

\begin{tabular}{lccccccccc}
\hline \multicolumn{1}{c}{ Variabel } & B & S.E. & Wald & Df & Sig. & Exp (B) & Lower & Upper \\
\cline { 8 - 10 } & & & & & & & & & \\
\cline { 7 - 10 } & Personal Hygiene & 1,503 & 0,701 & 4,601 & 1 & 0,032 & 4,494 & 1,138 & 17,744 \\
Jenis Pekerjaan & 1,163 & 0,776 & 2,247 & 1 & 0,134 & 3,198 & 0,699 & 14,626 \\
Pengetahuan & 2,477 & 0,794 & 9,725 & 1 & 0,002 & 11,903 & 2,510 & 56,452 \\
Riwayat Kontak & 3,162 & 0,872 & 13,143 & 1 & 0,000 & 23,613 & 4,273 & 130,469 \\
Akses Yankes & 0,898 & 0,700 & 1,647 & 1 & 0,199 & 2,454 & 0,623 & 9,668 \\
Fisik Rumah & 0,884 & 0,704 & 1,575 & 1 & 0,210 & 2,420 & 0,609 & 9,625 \\
Sumber AirBersih & 0,958 & 0,712 & 1,815 & 1 & 0,178 & 2,608 & 0,647 & 10,518 \\
Kelembaban & 2,852 & 0,880 & 10,495 & 1 & 0,001 & 17,326 & 3,085 & 97,296 \\
Suhu & 2,424 & 0,831 & 8,506 & 1 & 0,004 & 11,291 & 2,214 & 57,568 \\
\hline
\end{tabular}

Sumber : Data Primer, 2020

\section{PEMBAHASAN}

1. Penyakit kusta lebih banyak terjadi pada responden yang tidak mempunyai perilaku personal hygiene baik sebanyak 21 orang (72,4\%) dibandingkan dengan responden yang mempunyai perilaku personal hygiene baik sebanyak 8 orang $(27,6 \%)$. Hasil uji statistik dengan uji Chi-Square diperoleh nilai $p(0,003)<\alpha \quad(0,05)$. Responden dengan personal hygiene kurang lebih rentan untuk terkena kusta dibandingka dengan yang personal hygienenya baik, karena perilaku personal hygiene yang kurang dapat menjadi resiko berkembangbiaknya bakteri kusta.

2. Penyakit kusta lebih banyak terjadi pada responden yang berumur $\geq 20$ tahun sebanyak 23 orang $(79,3 \%)$ dibandingkan dengan responden yang berumur $<20$ tahun sebanyak 6 orang $(20,7 \%)$. Hasil uji statistik dengan uji Chi-Square diperoleh nilai $p(0,472)>\alpha$ $(0,05)$. Umur salah satu unsur penting dalam terjadinya kejadian dan penyebaran penyakit, karena umur mempengaruhi tingkat imunitas dan kekebalan. Sebagian besar responden berumur $\geq 20$ tahun sehingga penyakit kusta lebih banyak terjadi pada responden yang berumur $\geq 20$ tahun. 
3. Penyakit kusta lebih banyak terjadi pada responden yang berjenis kelamin perempuan sebanyak 17 orang $(58,6 \%)$ dibandingkan dengan responden yang berjenis kelamin sebanyak 12 orang (41,4\%). Hasil uji statistik dengan uji Chi-Square diperoleh nilai $p(0,829)>\alpha$ $(0,05)$, sehingga dapat disimpulkan bahwa Ho diterima yang artinya tidak ada hubungan yang bermakna antara berjenis kelamin dengan terjadinya penyakit kusta.

4. Penyakit kusta lebih banyak terjadi pada responden yang mempunyai tingkat pendidikan rendah sebanyak 17 orang $(58,6 \%)$ dibandingkan dengan responden yang mempunyai tingkat pendidikan sedang sebanyak 12 orang $(41,4 \%)$. Hasil uji statistik dengan uji Chi-Square diperoleh nilai $\mathrm{p}(0,105)>\alpha$ $(0,05)$. Tingkat pendidikan yang rendah menyebabkan pengetahuan seseorang akan kesehatan sangat kurang, yang berimbas pada perilaku sehari-harinya yang tidak sehat. Penderita kusta sebagian besar merupakan orang-orang dengan ekonomi rendah dan tingkat pendidikan rendah. ${ }^{10}$

5. Penyakit kusta lebih banyak terjadi pada responden yang mempunyai jenis pekerjaan buruh sebanyak 22 orang (75,9\%) dibandingkan dengan responden yang mempunyai jenis pekerjaan pekerja sebanyak 7 orang $(24,1 \%)$. Hasil uji statistik dengan uji Chi-Square diperoleh nilai $p(0,023)<\alpha$ $(0,05)$. Salah satu faktor risiko kejadian penyakit kusta adalah jenis pekerjaan. Pekerjaan sebagai petani dan buruh berisiko 3,5 kali terhadap kejadian penyakit kusta dibanding dengan orang yang pekerjaannya bukan petani atau buruh. Responden yang bekerja sebagai buruh lebih rentan terkena kusta dibandingkan dengan responden yang bekerja di perkantoran.

6. Penyakit kusta lebih banyak terjadi pada responden yang penghasilannya < 4.039.067 sebanyak 17 orang $(58,6 \%)$ dibandingkan dengan responden yang penghasilannya $\geq 4.039 .067$ sebanyak 12 orang $(41,4 \%)$. Hasil uji statistik dengan uji Chi-Square diperoleh nilai $p$ $(0,453)>\alpha(0,05)$. Penyakit kusta terdapat di negara berkembang dan sebagian besar adalah dari golongan ekonomi lemah. Hal ini disebabkan oleh keterbatasan kemampuan negara dalam memberikan pelayanan yang memadai di bidang kesehatan, pendidikan. ${ }^{11}$ Penghasilan yang rendah menyebabkan seseorang tidak dapat melakukan perawatan yang baik bagi kesehatannya.

7. Penyakit kusta lebih banyak terjadi pada responden yang tidak 
berpengetahuan sebanyak 20 orang (69\%) dibandingkan dengan responden yang berpengetahuan sebanyak 9 orang (31\%). Hasil uji statistik dengan uji ChiSquare diperoleh nilai $p(0,007)<\alpha$ $(0,05)$. Pengetahuan responden dapat membuatnya melakukan pencegahan terhadap penyakit kusta.

8. Penyakit kusta lebih banyak terjadi pada responden yang mempunyai riwayat kontak sebanyak 18 orang $(62,1 \%)$ dibandingkan dengan responden yang tidak mempunyai riwayat kontak sebanyak 11 orang $(37,9 \%)$. Hasil uji statistik dengan uji Chi-Square diperoleh nilai $p(0,000)<\alpha$ $(0,05)$. Orang-orang disekitar penderita kusta yang melakukan kontak secara langsung seperti anggota keluarga yang merawat dan tenaga kesehatan perlu melakukan tindakan antisipasi seperti menggunakan APD pada saat melakukan kontak dengan penderita kusta.

9. Penyakit kusta lebih banyak terjadi pada responden yang mempunyai akses terhadap pelayanan kesehatan jauh sebanyak 18 orang (62,1\%) dibandingkan dengan responden yang mempunyai akses terhadap pelayanan kesehatan tidak jauh sebanyak 11 orang $(37,9 \%)$. Hasil uji statistik dengan uji Chi-Square diperoleh nilai $\mathrm{p}(0,238)>\alpha$
$(0,05)$. Pelayanan kesehatan merupakan salah satu faktor yang mempengaruhi status kesehatan masyarakat, selain perilaku, lingkungan dan keturunan, berdasarkan penelitian yang dilakukan jarak pelayanan kesehatan mempengaruhi masyarakat untuk melakukan pengobatan ke pelayanan kesehatan. Responden pada umumnya tinggal jauh dari pelayanan kesehatan, dan akses transportasi yang sulit dan mahal.

10. Penyakit kusta lebih banyak terjadi pada responden yang mempunyai kondisi fisik rumah tidak sehat sebanyak 21 orang $(72,4 \%)$ dibandingkan dengan responden yang mempunyai kondisi fisik rumah sehat sebanyak 8 orang $(27,6 \%)$. Hasil uji statistik dengan uji Chi-Square diperoleh nilai $p(0,001)<\alpha(0,05)$. Kondisi fisik rumah, mencakup jenis bahan bangunan rumah dan lokasi rumah seperti jenis dinding, lantai dan atap. Jenis bahan bangunan rumah akan mempengaruhi peresapan air dan jumlah debu dalam rumah.

11. Penyakit kusta lebih banyak terjadi pada responden yang mempunyai sumber air sungai sebanyak 20 orang (69\%) dibandingkan dengan responden yang mempunyai sumber air tanah sebanyak 9 orang (31\%). Hasil uji 
statistik dengan uji Chi-Square diperoleh nilai $p(0,005)<\alpha(0,05)$. Kelompok yang beresiko terkena kusta adalah yang tinggal di daerah endemik dengan kondisi yang buruk seperti lingkungan tempat tinggal yang tidak memadai, air yang tidak bersih, asupan gizi yang buruk, dan adanya penyertaan penyakit lain seperti HIV yang dapat menekan sistem imun. ${ }^{12}$ Sumber air berkaitan dengan kemampuan melakukan personal hygiene yang baik.

12. Penyakit kusta lebih banyak terjadi pada responden yang mempunyai ventilasi tidak memenuhi syarat sebanyak 18 orang $(62,1 \%)$ dibandingkan dengan responden yang mempunyai ventilasi memenuhi syarat sebanyak 11 orang (37,9\%). Hasil uji statistik dengan uji Chi-Square diperoleh nilai $p(0,107)>\alpha(0,05)$. Apabila ventilasi kamar baik, kuman ini dapat hilang terbawa angin dan akan lebih baik jika ventilasi ruangannya menggunakan pembersih udara yang bias menangkap kuman.

13. Penyakit kusta lebih banyak terjadi pada responden yang mempunyai pencahayaan tidak memenuhi syarat sebanyak 17 orang $(58,6 \%)$ dibandingkan dengan responden yang mempunyai pencahayaan memenuhi syarat sebanyak 12 orang (41,4\%). Hasil uji statistik dengan uji Chi-Square diperoleh nilai $p(0,283)>\alpha(0,05)$. Pencahayaan yang baik adalah yang berasal dari cahaya matahari. Penderita kusta terutama di daerah yang padat penduduk tidak mempunyai akses terhadap cayaha matahari yang banyak karena takut dan malu untuk keluar rumah, sedangkan pencahayaan di dalam rumahnya kurang.

14. Penyakit kusta lebih banyak terjadi pada responden yang mempunyai kelembaban tidak memenuhi syarat sebanyak 18 orang $(62,1 \%)$ dibandingkan dengan responden yang mempunyai kelembaban memenuhi syarat sebanyak 11 orang $(37,9 \%)$. Hasil uji statistik dengan uji Chi-Square diperoleh nilai $p(0,006)<\alpha(0,05)$. Tingkat kelembaban yang tidak memenuhi syarat dapat menjadi penunjang terjadinya kusta.

15. Penyakit kusta lebih banyak terjadi pada responden yang mempunyai suhu tidak berisiko sebanyak 12 orang $(41,4 \%)$ dibandingkan dengan responden yang mempunyai suhu berisiko sebanyak 17 orang (58,6\%). Hasil uji statistik dengan uji Chi-Square diperoleh nilai $p(0,028)<\alpha(0,05)$. Di luar tubuh manusia (dalam kondisi tropis) kuman kusta dari sekret nasal dapat bertahan sampai 9 hari. 
Pertumbuhan optimal in vivo kuman kusta pada tikus pada suhu $27^{\circ}-30^{\circ} \mathrm{C}^{13}$ Suhu yang berisiko dapat menjadi media berkembangnya bakteri penyebab penyakit kusta.

16. Penyakit kusta lebih banyak terjadi pada responden yang mempunyai tingkat tingkat sedang berat sebanyak 11 orang (37,9\%) dibandingkan dengan responden yang mempunyai tingkat stres ringan sebanyak 9 orang (31,0\%), yang mempunyai tingkat stres ringan sebanyak 6 orang $(20,7 \%)$, dan yang mempunyai tingkat stres normal sebanyak 3 orang (10,3\%). Hasil uji statistik dengan uji Chi-Square diperoleh nilai $p(0,283)>\alpha(0,05)$. Stres dapat terjadi pada setiap orang dengan tingkatan yang berbeda dan disebabkan oleh faktor yang berbeda pula.

17. Penyakit kusta lebih banyak terjadi pada responden yang tidak mempunyai keturunan penyakit kusta sebanyak 23 orang $(79,3 \%)$ dibandingkan dengan responden yang mempunyai keturunan penyakit kusta sebanyak 6 orang $(20,7 \%)$. Hasil uji statistik dengan uji Chi-Square diperoleh nilai $p(0,263)>\alpha$ $(0,05)$. Faktor genetik telah lama dipertimbangkan karena mempunyai peranan besar untuk terjadinya penyakit kusta pada kelompok tertentu. Faktor genetik yang berperan salah satunya adalah berada di bawah sistem Human Leucocyte Antigen (HLA). ${ }^{14}$

18. Variabel yang paling dominan terhadap terjadinya penyakit kusta adalah variabel riwayat kontak ( $P$-value:0,000) dengan OR paling tinggi yaitu 26,823. Sumber utama penularan penyakit kusta adalah manusia. Jika ada seseorang yang menderita penyakit kusta dan tidak ditangani dengan tepat, sewaktu-waktu bakteri lepra akan menyebar melalui udara dan kemungkinan besar akan menularkan kepada orang yang disekitarnya. Selain itu juga, penularan juga bisa melalui benda-benda yang biasa digunakan oleh penderitanya. Penyakit lepra juga mudah ditularkan melalui hubungan yang dekat dengan penderita lepra itu sendiri. Biasanya, mereka yang tinggal satu rumah dengan penderita kusta akan mudah tertular. $^{9}$

\section{KESIMPULAN}

Hasil penelitian menunjukkan bahwa terdapat hubungan yang bermakna antara personal hygiene (P-value:0,003), jenis pekerjaan ( $P$-value:0,023), pengetahuan (P-value:0,007), riwayat kontak (P-value:0,000), kondisi fisik rumah (P-value:0,001), sumber air bersih (P-value:0,005), kelembaban (P-value:0,006), dan suhu (P-value:0,028) 
dengan terjadinya penyakit kusta. Variabel yang paling dominan terhadap terjadinya penyakit kusta adalah riwayat kontak (OR $23,613)$, artinya orang yang mempunyai riwayat kontak dengan pasien kusta berisiko 23,613 kali lebih besar terpapar penyakit kusta dibandingkan dengan orang yang tidak mempunyai riwayat kontak dengan pasien kusta.

\section{DAFTAR PUSTAKA}

1. WHO https://apps.who.int/neglect ed diseases/ntddata/leprosy/leprosy .html. Diakses 20 maret 2019

2. Profil Kesehatan Dinas Kesehatan Provinsi Jawa Barat 2018.

3. Profil Dinas Kesehatan Kabupaten Purwakarta 2019.

4. Profil Kesehatan UPTD Puskesmas Sukatani Kabupaten Purwakarta Tahun 2019.

5. Kemenkes RI. Pedoman Nasional Program Pengendalian Penyakit Kusta. (2012).

6. Muharry. Faktor Resiko Kejadian Kusta. Sekolah Tinggi Ilmu Kesehatan Kuningan (STIKKu) Jalan Lingkar Kadugede No.02 Kuningan, Indonesia. Jurnal Kesehatan Masyarakat. Kemas 9 (2) (2014) 174-182. (2014)

7. Tarmisi A, dkk. Analisis Risiko High Endemis di Desa Air Panas Kecamatan Parigi Barat Kabupaten Parigi Moutong.
Jurnal Kesehatan Tadulako Vol. 2 No. 1, Januari 2016

8. Aprizal, lazuardi L, Soebono H. Faktor Resiko Kejadian Kusta di Kabupaten Lamongan. Berita Kedokteran Masyarakat Volume 33 No 9. HIm 427432. FKM Universitas Gajah Mada. (2017)

9. Noviya R. Buku Cerdik Penyakit-Penyakit Menular. Saufa: Yogyakarta. (2014).

10. Maharani A. Penyakit kulit Perawatan, Pencegahan, Pengobatan. Pustaka Baru Press: Yogyakarta. (2015).

11. Saragih, dkk. Gambaran Epidemiologi Penyakus Kusta di Kecamatan Sui Kakap Kabupaten Kubu Raya Provinsi Kalimantan Barat. FK Tanjung Pura: Kalimantan Barat. (2012).

12. Rachmalina \& Susanti. Penanggulangan Penyakit Kusta Pada Daerah Endemis dengan Pendekatan Sosial Budaya di Kabupaten Bangkalan. (1999).

13. Departemen Kesehatan Republik Indonesia, Pedoman Nasional Pengendalian Penyakit Kusta, Jakarta : Depkes RI. (2007).

14. Hadi H, Kumalasari. Kusta Stadium Subklinis dan permasalahannya. Universitas Islam Negri Sunan Ampel. (2017). 